\title{
LIPOPHAGY: a novel form of steroidogenic activity within the LEYDIG cell during the reproductive cycle of turtle
}

\author{
Imran Tarique', Waseem Ali Vistro' ${ }^{1}$, Xuebing Bai' ${ }^{1}$ Ping Yang ${ }^{1}$, Chen Hong ${ }^{1}$, Yufei Huang ${ }^{1}$, Abdul Haseeb ${ }^{1,2}$, \\ Enxue Liu', Noor Samad Gandahi', Mengdi Xu' ${ }^{1}$ Yifei Liu' and Qiusheng Chen ${ }^{1 *}$ (D)
}

\begin{abstract}
Background: Steroidogenesis is an indispensable process that is indirectly associated with spermatogenesis in the Leydig cell (LC) to utilize the lipid droplets (LDs) that are critical to maintaining normal testosterone synthesis. The regulation of LD mobilization, known as lipophagy, in the LC is still largely unknown.

Method: In the present study, the LC of the Chinese soft-shelled turtle was investigated to identify the steroidogenic activity and lipophagy during the annual reproductive cycle by light microscopy, immunohistochemistry (IHC), immunofluorescence (IF), and transmission electron microscopy (TEM).

Results: The LC showed a dynamic steroidogenic function with strong activity of 3 $\beta-H S D$, vimentin and tubular ER during hibernation by IHC and TEM. The tubulo-vesicular ER had a weak immunopositive reaction for 3ß-HSD in the LC during reproductive phase, suggesting persistent steroidogenic activity. ORO staining and TEM demonstrated that a larger number of LDs had accumulated in the LC during hibernation than in the reproductive phase. These LDs existed in close association with mitochondria and lysosomes by being dynamically surrounded by intermediate filaments to facilitate LD utilization. Lysosomes were found directly attached to large LDs, forming an autophagic tube and engulfing LDs, suggesting that micro-lipophagy occurs during hibernation. Furthermore, the IHC of ATG7 (Autophagy Related Gene 7) and the IF of the LC3 (Microtubule-associated protein light chain 3), p62 (Sequestosome-1 (SQSTM1) and LAMP1(Lysosomal-associated membrane protein 1) results demonstrated strong expression, and further confirmation by TEM showed the existence of an autophagosome and an autolysosome and their fusion during the hibernation season.

Conclusion: In conclusion, the present study provides clear evidence of LD consumption in the LC by lipophagy, lysosome and mitochondria during the hibernation period, which is a key aspect of steroidogenesis in the Chinese softshelled turtle.
\end{abstract}

Keywords: Leydig cell, Lipophagy, Hibernation, LC3, 33-HSD, Chinese soft-shelled turtle

\section{Background}

The adult male testis has two significant roles, the production of spermatozoa and the secretion of sexual steroids [1]. Like other vertebrates, these two important functions in reptiles occur in the tubular and interstitial compartments of the testis, respectively. Spermatogenesis occurs within the seminiferous tubules (ST). However, the male specific, Leydig

\footnotetext{
* Correspondence: chenqsh305@njau.edu.cn

${ }^{1} \mathrm{MOE}$ Joint international Research Laboratory of Animal Health and Food safety, College of Veterinary Medicine, Nanjing Agricultural University, Nanjing 210095, Jiangsu Province, China

Full list of author information is available at the end of the article
}

cells (LC), which are distributed in the interstitial tissues are accountable for androgen hormone production and play a critical role in spermatogenesis [2]. It is well-known that many mammals have an associated reproductive pattern. In some seasonally breeding reptilian species, separate hormonal cues initiate spermatogenesis and mating, which is so-called dissociated reproductive pattern [3-5]. Spermatogenesis in the Chinese soft-shelled turtle is an annual event that is active in late spring, summer and fall (May to October) and ends with one massive release of sperm in late October or early November. This species remains quiescent (the hibernation period) throughout the rest of the year

(c) The Author(s). 2019 Open Access This article is distributed under the terms of the Creative Commons Attribution 4.0 International License (http://creativecommons.org/licenses/by/4.0/), which permits unrestricted use, distribution, and reproduction in any medium, provided you give appropriate credit to the original author(s) and the source, provide a link to the Creative Commons license, and indicate if changes were made. The Creative Commons Public Domain Dedication waiver (http://creativecommons.org/publicdomain/zero/1.0/) applies to the data made available in this article, unless otherwise stated. 
(December to April) [6]. During the testicular cycle, structural changes in the male germinal epithelium have been associated with fluctuating reproductive patterns and variation in LC activity [7-9]. Previously, our research group produced detailed cellular work on the germ cell, Sertoli cell and their novel role during the annual cycle $[10,11]$, but an ultrastructural analysis of the LC in the Chinese shelled-turtle has not been reported.

Leydig cells are characterized by lipid droplets and composed of neutral lipid cores, mainly made up of cholesteryl esters and triglycerides [12]. The sequestration of lipids in droplet form provides a depot of stored energy that can be accessed in a regulated fashion according to cellular need. Recently, it has been reported that autophagy regulates testosterone biosynthesis [13] by facilitating cholesterol uptake [14] and regulating fertility [15] in rats. Autophagy of lipid droplets, or lipophagy is an alternative to lipolysis. It is characterized by a spherical double membrane structure known as an autophagosome. The autophagosome is subsequently fused with the lysosome to form an autolysosome. The contents of the autolysosome are then degraded by the lysosomal hydrolytic enzymes, which release the contents into the cytoplasm [16]. Another type of autophagy is microlipophagy, which is characterized by the direct interaction of lysosome and the lipid droplet, where the contents enter the lysosome through an invagination or deformation of the lysosomal membrane [17]. During the past few decades, the interaction between lysosomes and lipid droplets have become a focus for research. The lysosome is a key organelle in autophagy and coordinates the sorting, recycling and delivery of endogenous lipids [18].

The LC3 and p62 biomarkers are widely used for monitoring autophagy [19]. LC3 is a soluble protein which is distributed ubiquitously in mammalian tissues. During autophagy, LC3-I is conjugated to phosphatidylethanolamine to form an LC3-phosphatidylethanolamine conjugate (LC3-II), which is tightly bound to the autophagosomal membranes [20]. The $\mathrm{p} 62$ protein, also called sequestosome 1 (SQSTM1), helps with the recognition of autophagic cargo in numerous cell types [21]. ATG 7 is one important member of an autophagy-related gene family that encodes the E1-like enzyme, which facilitates both LC3 and other autophagy- related genes [22-24]. The well-known proteins called LAMP1 and LAMP2 are commonly used for lysosomes. Recently, it has been suggested that LAMP1 binds to fatty molecules and cholesterol is involved in lysosomal cholesterol dissemination [25]. Together with these findings, Leydig cells and autophagy have also been studied in mammals by using the traditional method of electron microscopy [26, 27].

Autophagy is a conserved system among eukaryotes and is well-studied in mammals [12]. It also contributes to the adaptive response to starvation and various, extrinsic and intrinsic stresses. Nevertheless, its role in reptilian Leydig cells is still largely unknown. The Chinese soft-shelled turtle (Pelodiscus sinensis) is one of the most economical and pharmacologically worthy reptiles in China. As a seasonally breeding animal, this species is an excellent model for studying the regulation of reproductive activity. The objectives of the current study were to analyze the seasonal ultrastructural changes in the Leydig cell and to explore lipophagy and the consumption of LDs within the testis of the Chinese soft-shelled turtle.

\section{Methods \\ Experiment animals}

Pelodiscus sinensis soft-shelled turtles (mature males, $>3$ years of age) were purchased from an aquatic farm in the Nanjing, Jiangsu province of China in March and October, with six turtles for each time period. The animals were rendered comatose using intraperitoneally administered sodium pentobarbital $(20 \mathrm{mg} / \mathrm{animal})$ and were sacrificed by cervical dislocation. The testes were collected immediately and fixed to perform the different techniques (details below).

\section{Light microscopy}

The testis samples were placed in 10\% neutral buffered formalin for fixation overnight, and then embedded in paraffin wax. Sectioning was done at $5 \mu \mathrm{m}$. These sections were stained with haematoxylin and eosin procedures (Harry's haematoxyline for $2 \mathrm{~min}$ and $1 \%$ eosin for $30 \mathrm{~s}$ ). For light microscope analysis using an Olympus microscope (BX53) and camera (Olympus DP73, Japan).

\section{Oil red O (ORO) staining}

Testis samples ( $5 \mu \mathrm{m}$ thick frozen slices) were washed with PBS, fixed with $4 \%$ formaldehyde for $10 \mathrm{~min}$, and stained with ORO staining (Sigma) solution (oil O saturated solution in isopropanol: water, 3:2) for $15 \mathrm{~min}$. After staining slides, washed with warm distilled water $\left(37^{\circ} \mathrm{C}\right)$ for $15 \mathrm{~min}$. Subsequently, counterstained with hematoxylin for $2 \mathrm{~min}$, and were rinsed with tap water for $60 \mathrm{~s}$.

\section{Immunohistochemistry (IHC)}

The paraffin sections prepared on glass slides were briefly deparaffinized and washed with phosphate buffered saline (PBS). To block any further activity forms of endogenous peroxidases, the sections were treated with $3 \%$ hydrogen peroxide $\left(\mathrm{H}_{2} \mathrm{O}_{2}\right)$ in PBS for $15 \mathrm{~min}$ at $37^{\circ} \mathrm{C}$. The samples were then treated with $5 \%$ bovine serum albumin (BSA 5\%) and incubated with a primary antibody (Table 1 ) in a moisture chamber at $4{ }^{\circ} \mathrm{C}$ for $24 \mathrm{~h}$, while PBS ( $\mathrm{pH}$ 7.2) served as the negative control. After washing, the sections were incubated with the secondary antibody for $1 \mathrm{~h}$ at room temperature. The sections were then rehydrated in PBS (pH 7.2) and incubated with an avidin-biotinylated peroxidase complex for $45 \mathrm{~min}$ at $37^{\circ} \mathrm{C}$. After being washed with PBS, peroxidase activity was revealed using DAB (Boster 
Table 1 The information for primary and secondary antibodies

\begin{tabular}{|c|c|c|c|c|}
\hline & Species & Catalog No. & Dilution & Source \\
\hline \multicolumn{5}{|c|}{ Primary antibodies } \\
\hline Vimentin & Rabbit & Bs-0756R & 1:100 & Bioss ANTIBODIES \\
\hline 3Beta-HSD & Rabbit & A1823 & $1: 100$ & ABclonol Technology \\
\hline LAMP1 & Rabbit & $55,273-1-A P$ & $1: 100$ & Proteintech \\
\hline ATG7 & Rabbit & $10,088-2-A P$ & $1: 100$ & Proteintech \\
\hline LC3 & Rabbit & $12,135-1-A P$ & 1:100 & Proteintech \\
\hline P62 & Rabbit & 51,145 & 1:100 & $\begin{array}{l}\text { Cell Signaling } \\
\text { Technology }\end{array}$ \\
\hline \multicolumn{5}{|c|}{ Secondary antibodies } \\
\hline \multicolumn{2}{|c|}{$\begin{array}{l}\text { AlexaFlour } 488 \\
\text { Gaot anti-rabbit } \\
\text { lgG }\end{array}$} & FMS-RBaf48801 & 1:100 & FCMACS \\
\hline \multicolumn{2}{|c|}{ Anti-rabbit igG } & KIT-5004/5/6 & & MXB Biotechnology \\
\hline
\end{tabular}

Bio-Technology Co., LTD), according to the manufacturer's instructions.

\section{Immunofluorescence (IF)}

The paraffin sections were incubated with a primary antibody overnight at $4{ }^{\circ} \mathrm{C}$. Following the primary antibody
(Table 1) application, all the samples were incubated with a secondary antibody for $1 \mathrm{~h}$ at $4{ }^{\circ} \mathrm{C}$ and were rehydrated in PBS. For negative control PBS ( $\mathrm{pH} 7.2)$ was used. The sections were incubated with DAPI (4', 6-diamidino2-phenylindole $=$ nuclear staining) and were stimulated under a fluorescence microscope over time. All the specimens were initially viewed using an LED to visualize the fluorescence under the microscope. Photographs were taken of every section of the specimen at 40-400x magnification power.

\section{Transmission electron microscopy (TEM)}

For the ultrastructural analysis, testis specimens were cut into small parts $\left(1 \mathrm{~mm}^{3}\right)$ and fixed in $2.5 \%(\mathrm{v} / \mathrm{v})$ glutaraldehyde in $0.1 \mathrm{M}$ phosphate-buffered saline (PBS; $4{ }^{\circ} \mathrm{C}, \mathrm{pH} 7.4$; overnight). Thereafter, they were post-fixed with $1 \%(w / v)$ osmium tetroxide in the same buffer for $1 \mathrm{~h}$ and washed in the buffer. The samples were dehydrated with increasing concentrations of ethanol and infiltrated with a propylene oxide-araldite mixture for embedding into araldite. The blocks were sectioned. Ultrathin sections $(50 \mathrm{~nm})$ were mounted on Formvar-coated grids and stained with uranyl

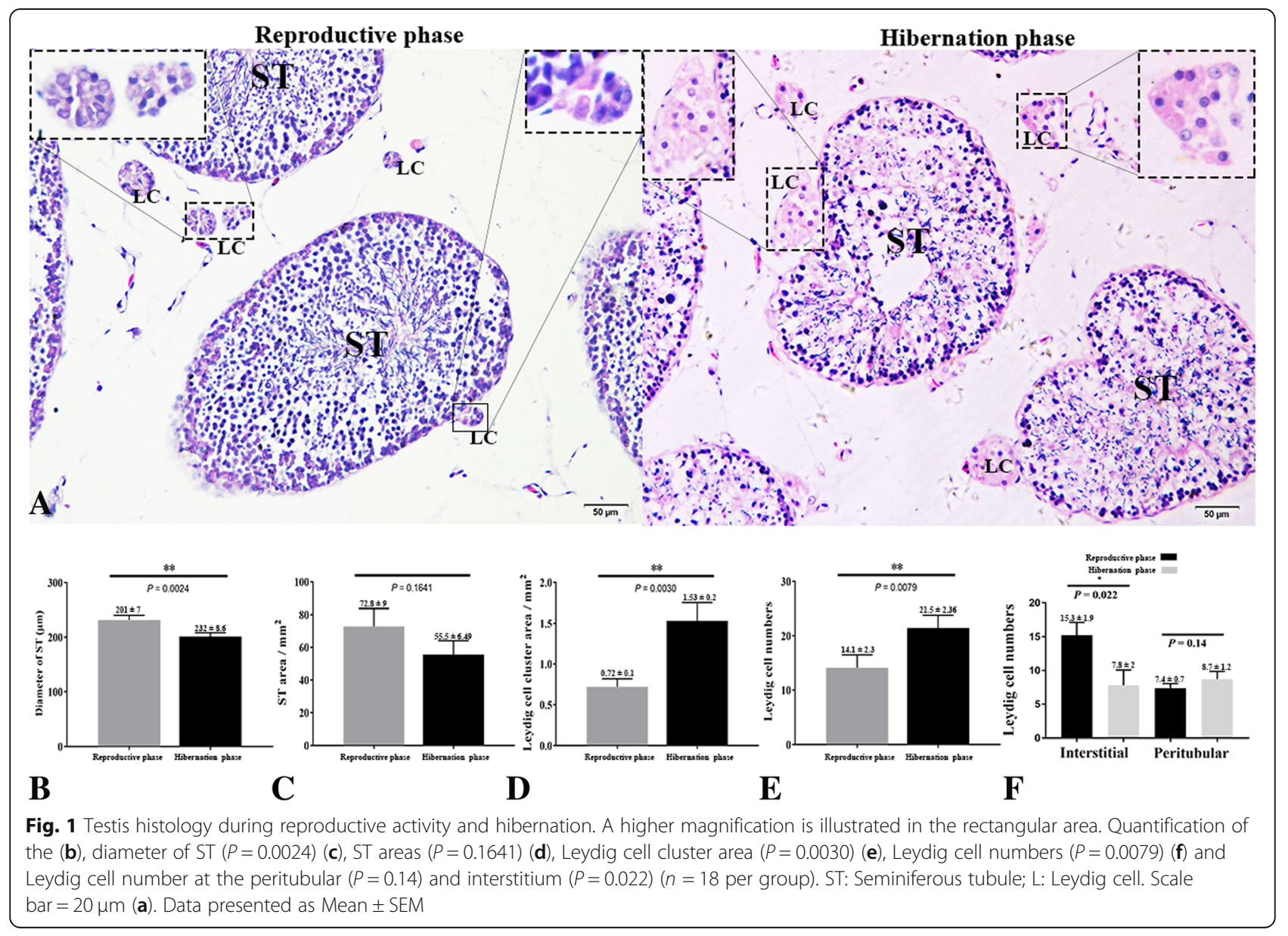




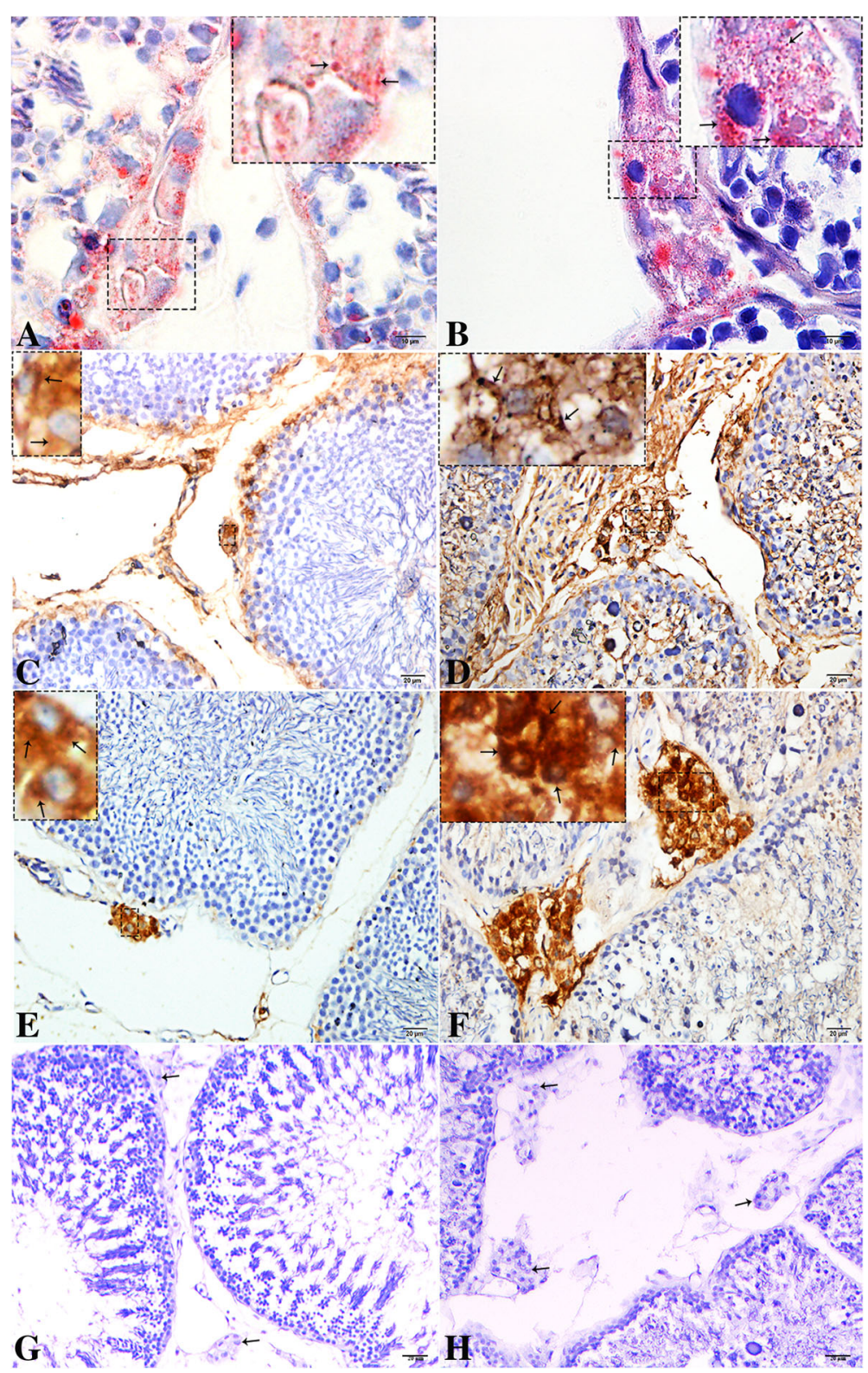

Fig. 2 Light micrograph of Oil Red O staining and immunohistochemistry of vimentin, and 3 $\beta-H S D$ in the testis during resproductive and hibernation phase. (a-b) ORO staining of lipid droplets (arrow), (c-d) vimentin (e-f) 3ß-HSD immunolocalization (arrow) and (G-H) negative control (arrow) in Leydig cell. A higher magnification is illustrated in the rectangular area. Scale bar $=10 \mu \mathrm{m}(\mathbf{a}-\mathbf{b})$ and $20 \mu \mathrm{m}(\mathbf{c}-\mathbf{h}) \mathrm{s}$

acetate and Reynolds led citrate for 20 min per step. The sections were analyzed with TEM (Hitachi H-7650; Japan).

\section{Statistical analysis}

To performed histo-morphometry of hematoxylin and eosin stained sections, from each sample $5 \mu \mathrm{m}$ serial sections were used. A total of 36 tissue sections with two replications of each analyses; equal numbers of tissue sections $(n=18)$ were taken from each group measured by Image Pro v10 and analyzed statistically and presented with Origin Pro 2018. The results were presented as the mean \pm
SEM. The statistical significance of differences among the means were analyzed by t-test $(P<0.05)$.

\section{Results}

Based on the histological analyses, the seminiferous tubules (ST) were lined with developing germ cells and permanent Sertoli cells during reproductive activity (Fig. 1a). Furthermore, a significantly higher diameter and area of ST were observed during the reproductive phase compared to the hibernation without a change in the ST area (Fig. 1b and c). During hibernation, the ST 


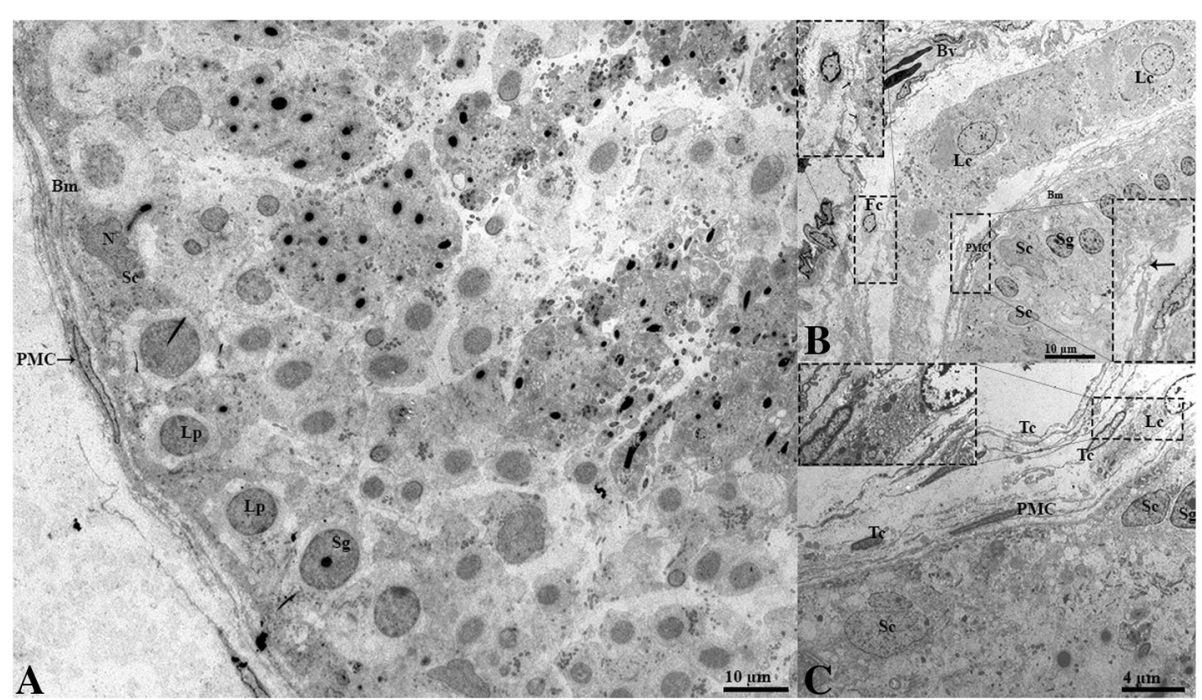

Fig. 3 Electron micrograph of the seminiferous tubules and the interstitium of the testis during reproductive phase. (a) Seminiferous tubules containing the maturing spermatocytes in the ad-lumen, spermatogonia and Sertoli cell at the basement membrane surrounded by peritubular myoid cells. (b-c) Interstitium space consisting of the Leydig cell, telocytes, fibroblasts and blood vessels. The higher magnification illustrates the contact between different the cells. Bm: basement membrane; Sc: Sertoli cell; N: Nucleus; Sg: spermatogonia; PMC: Peritubular myoid cell; Lc: Leydig cell; N: nucleus; Fc: Fibroblast; Tc: Telocyte; Bv: Blood vessel. Scale bar $=10 \mu \mathrm{m}$ (a-b) and $4 \mu \mathrm{m}$ (c)

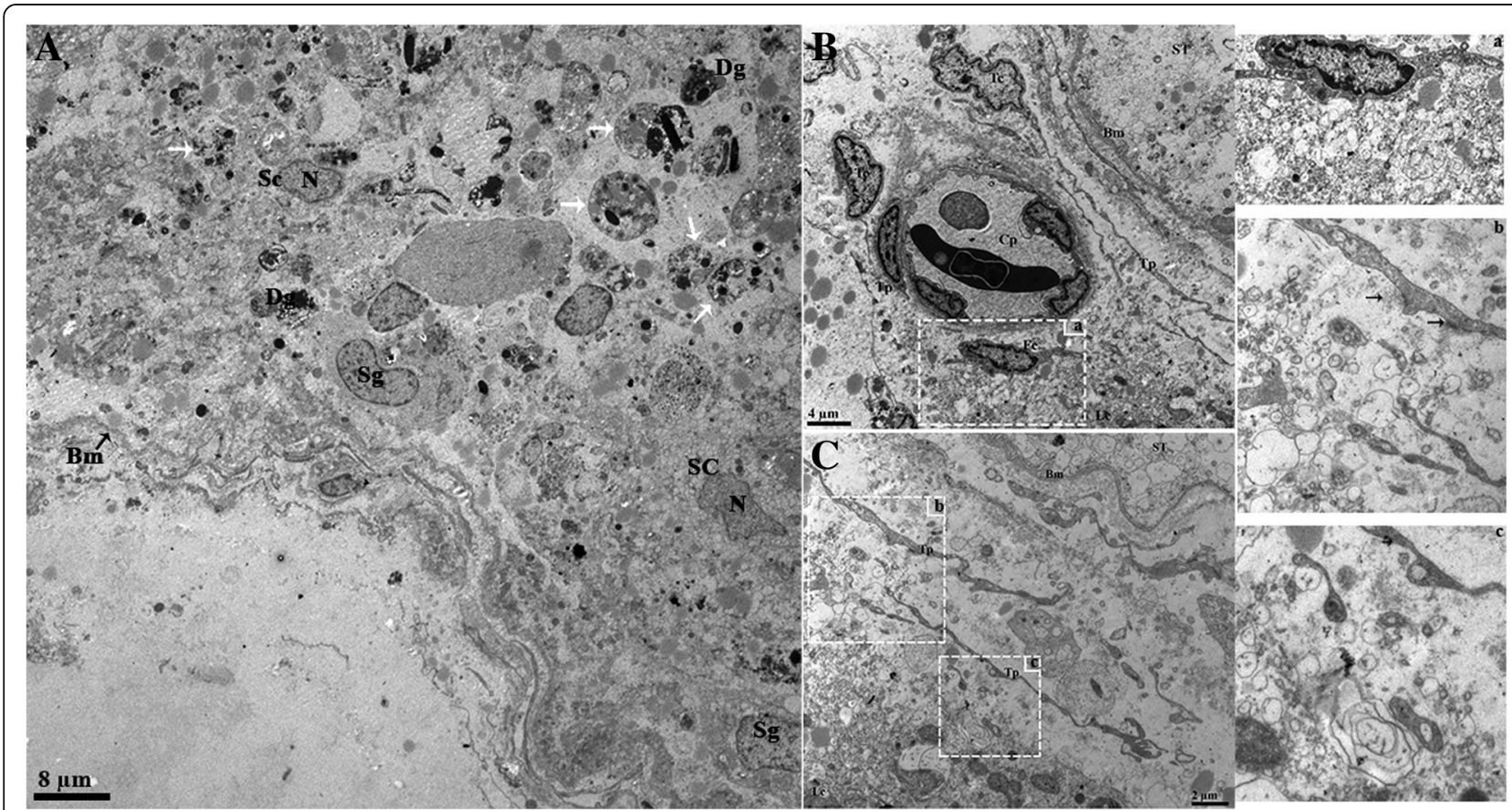

Fig. 4 Electron micrograph of seminiferous tubules and the interstitium of the testis during hibernation. (a) Seminiferous tubules containing various residual spermatids and entotic vesicles (white arrow) in the ad-lumen, spermatogonia and Sertoli cell at the basement membrane. (b-c) Interstitium consists Leydig cell, Telocyte, fibroblast and capillary. The higher magnification illustrates the contact between the different cells $(\mathbf{a}, \mathbf{b}, \mathbf{c})$. Bm: basement membrane; Sc: Sertoli cell; N: Nucleus; Sg: spermatogonia; PMC: Peritubular myoid cell; Lc: Leydig cell; N: nucleus; Fc: Fibroblast; Tc: Telocyte; Cp: Capillary. Scale bar $=8 \mu \mathrm{m}(\mathbf{a}), 4 \mu \mathrm{m}$ (b), and $2 \mu \mathrm{m}$ (c) 
showed residual spermatozoa and cleared ad-luminal compartments with decreased sperm numbers (Fig. 1a). The Leydig cells in the testis of the Chinese soft-shelled turtle were characterized by a compact morphology during reproductive phase and a significantly increased area during hibernation (Fig. 1a and d). The numbers of LC were statistically higher during hibernation than in reproductive phase (Fig. 1e). Additionally, the LC numbers at the interstitial position were significantly higher than at the peritubular position during reproductive phase, while those, at peritubular position were relatively higher during hibernation (Fig. 1f).

The light microscopic results of the ORO staining indicate on small LD content within the LC during reproductive phase (Fig. 2a), while large amount of LD was observed during hibernation (Fig. 2b). Immunoreactivity of vimentin was also weak during reproductive phase compared to a strong immunosignal during hibernation. The immunopositive reaction mainly appeared at the cytoplasmic membrane and around the nucleus (Fig. 2b and c). 3Beta-HSD is a key enzyme in the biosynthesis of steroid hormone. Its weak to moderate labeling was observed during reproductive phase, while moderate to intense immunosignal occurred during hibernation. The immunolabeling mainly appeared at the cytoplasm and close to the nucleus (Fig. 2e and d).

The ultrastructure of the seminiferous tubules during reproductive phase showed that the seminiferous epithelium was lined with numerous spermatids progressing into the various phases of spermiogenesis and that the lumen was filled with free spermatozoa (Fig. 3a). The interstitium showed the peritubular myoid cells, telocytes, and fibroblasts in contact with the LC. (Fig. 3b and c). In hibernation, the ST displayed depolarized residual spermatids, and the entotic vacuoles at the ad-luminal compartment were indicative of a clearing of previous spermatogenic residues (Fig. 4a). In the interstitial space, fibroblasts and telocytes displayed communication via vesicles with the LC (Fig. 4b and c).

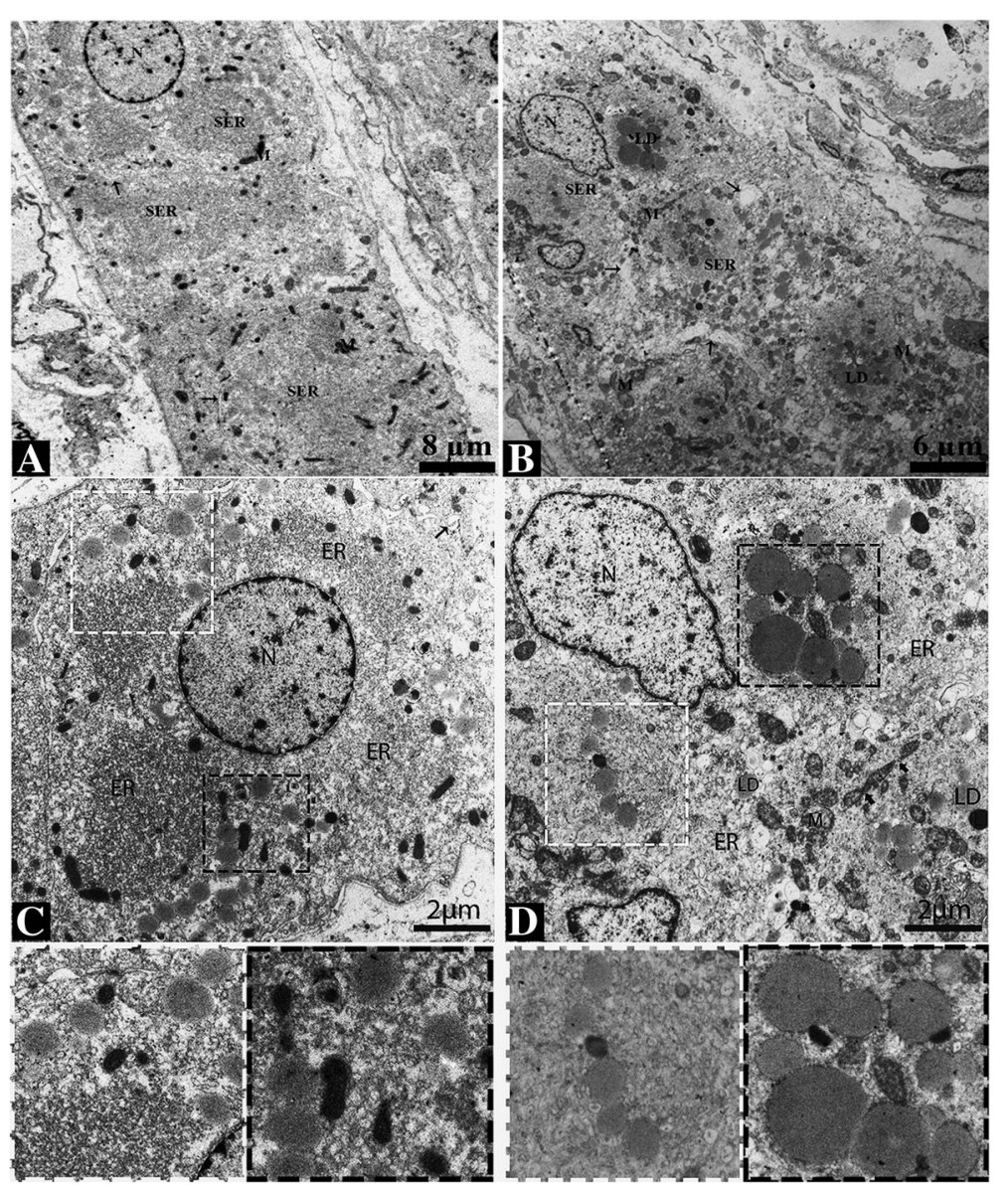

Fig. 5 Electron micrograph of the Leydig cell in the testis of the Chinese soft-shelled turtle. The Leydig cell is compactly exhibited during reproductive phase $(\mathbf{a})$ and loosely exhibited during hibernation phase (b) at the interstitium. The cytoplasm of the Leydig cell is rich in vesicular endoplasmic reticulum (c), lipid droplets, mitochondria and tubular endoplasmic reticulum (d). White thin arrow: gap junction; black thin arrow: finger-like prolongations in the interdigitation space; black thick arrow: dividing mitochondria. The illustration indicates a magnified view of the white and black square. N: nucleus; ER: endoplasmic reticulum; LD: lipid droplets; M: mitochondria. Scale bar = $8 \mu \mathrm{m}(\mathbf{a}), 6 \mu \mathrm{m}(\mathbf{b})$ and $2 \mu \mathrm{m}$ (c-d) 
In the reproductive phase, the LC displayed round eccentric nuclei with prominent nucleoli. The nucleoli possessed fine, electron dense, granulated euchromatin and heterochromatin, with the latter adjacent to the nuclear envelope. The nuclear envelope displayed nuclear pores and was surrounded by the endoplasmic reticulum. The cytoplasm showed interdigitation spaces with finger-like cytoplasmic projections and tight junctions (Figs. 5a, c and 6a). At the perinuclear cytoplasm, the vesicular endoplasmic reticulum was abundantly dispersed and in contact with the mitochondria and lipid droplets (Fig. $6 \mathrm{c}$ and e). In hibernation, the nucleus of LC appeared elongated with an irregular membrane. The tubular endoplasmic reticulum, lipid droplets, mitochondria and lysosomes were observed as predominant organelles in the LC cytoplasm during this period. The mitochondria were observed in the dividing state and in contact with the endoplasmic reticulum. (Fig. 5b and d). At the perinuclear cytoplasm, the tubular endoplasmic reticulum, mitochondria and lipid droplets were found to be in-contact with another (Fig. $6 \mathrm{~b}$ and d).

The autophagy markers evaluated by the immunohistochemistry of ATG7 signals were stronger during hibernation and weaker in reproductive phase. Moreover, LC3, p62 and LAMP1 had a strong spot-like immunosignals by immunofluorescence and were stronger during hibernation than the reproductive phase (Fig. 7). Additionally, the ultrastructure revealed that an extensive network of intermediate filaments surrounds the numerous large lipid droplets.

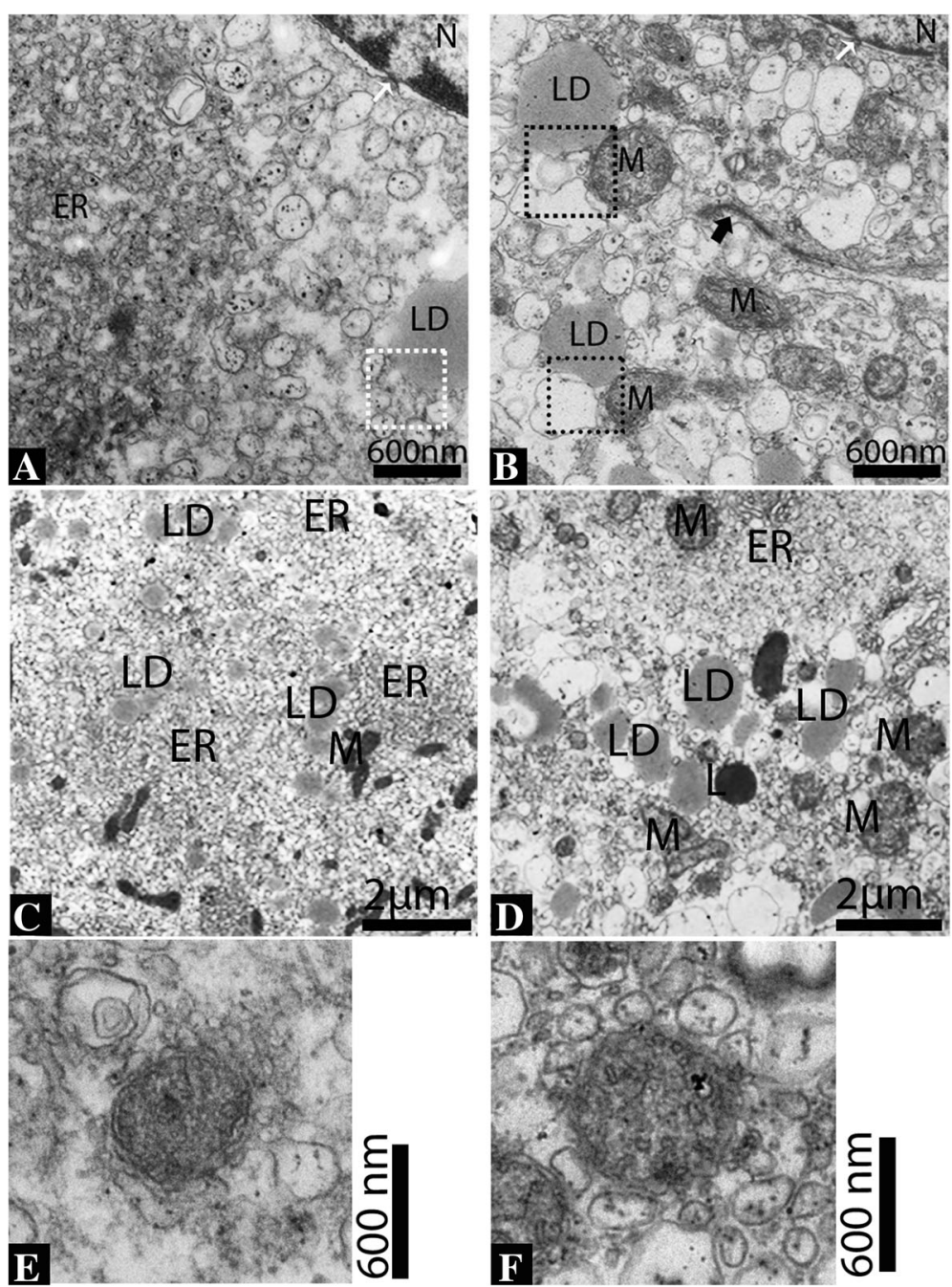

Fig. 6 Ultrastructure of the Leydig cell. Abundant vesicular endoplasmic reticulum (a), and tubular endoplasmic reticulum and mitochondria (b) appear close to the nucleus and also show the nucleus pores (white arrow). Lipid droplets exhibit closely with vesicular endoplasmic reticulum during reproductive phase (c). In hibernation, the tubular endoplasmic reticulum, mitochondria and lysosome appeared to be in contact with the lipid droplets (d). The endoplasmic reticulum in contact with a lipid droplet (white dotted square) and with a lipid droplet and the mitochondria (black dotted square). Tight junctions between Leydig cell are also seen (black thick arrow). Mitochondria with well-developed inter cristae tubules (e-f). N: nucleus; ER: endoplasmic reticulum; LD: lipid droplets; M: mitochondria; L: Lysosome. Scale bar $=600 \mu \mathrm{m}(\mathbf{a}-\mathbf{b}), 2 \mu \mathrm{m}=(\mathbf{c}-\mathbf{d})$ and $600 \mu \mathrm{m}(\mathbf{e}-\mathbf{f})$ 


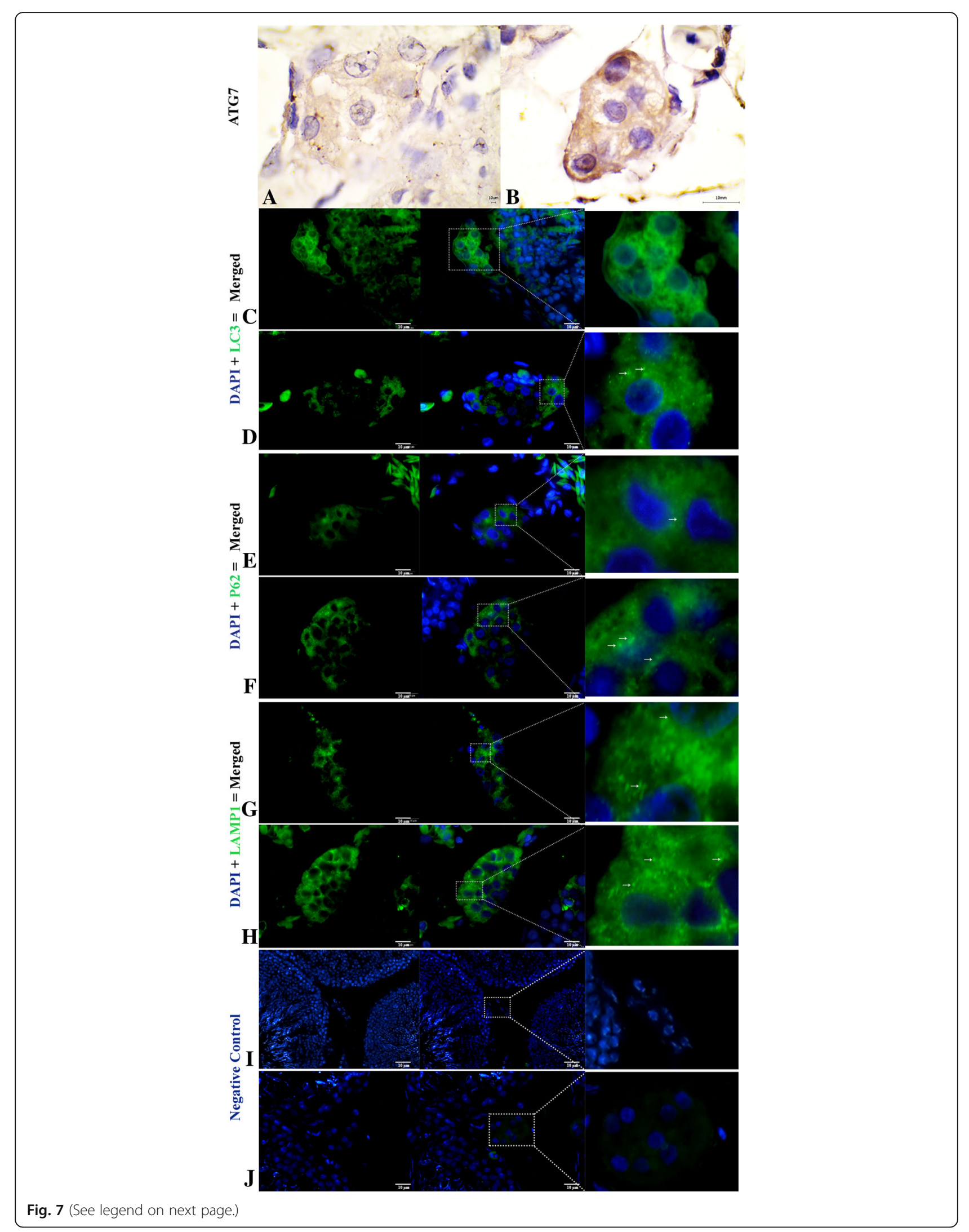


(See figure on previous page.)

Fig. 7 Immunofluorescent localization of autophagy markers in Leydig cells of the Chinese soft-shelled. Immunohistochemistry of ATG7 positive reactions in the Leydig cell (a-b). Immunofluorescence labeling of LC3, p62 and LAMP1 in the Leydig cell during reproductive (c, e and $\mathbf{g})$ and during hibernation phase (d, $\mathbf{f}$ and $\mathbf{h}$ ). Negative control; Reproductive (i) and hibernation phase (j). (White arrow): indicates positive localization. The higher magnification is illustrated by the rectangular area. Scale Bar $=10 \mu \mathrm{m}(\mathbf{a}-\mathbf{h})$

These lipid droplets were in contact with each other as well as with the mitochondria and lysosomes. Lysosomes were detected in contact with the LD, showing an autophagic tube and the engulfing of the LD. Several small lipid droplets, mitochondria and lysosomes were observed around the phagophore, within the LC during development of the autophagosome and autolysosome. (Fig. 8a and b).

We further summarized the characteristic features of the Leydig cells during the annual reproductive cycle of the Chinese soft-shelled turtle in the Table 2.

\section{Discussion}

The testicular morphology of the Chinese soft-shelled turtle was similar to that previously reported by our research group and in other reptiles [9, 28-30]. The dissociated reproductive pattern in the soft-shelled turtle indicates a seasonal activity in the tubular and interstitial compartments. The active reproductive phase was from May to Oct, and the quiescent or hibernation phase was from Nov to April [31]. During the quiescent phase, the seminiferous tubules regressed due to a single cohort releasing of spermatozoa into the epididymis. A parallel pattern was also found in Trionyx sinensis, which suggested the recrudescence of spermatogenesis [32]. Contrarily, mammals (rodents, monkeys, and human) produce sperm stored in the epididymis until ejaculation [33, 34]. After ejaculation, the principle activity of the Sertoli cell is removing the residual spermatids by apoptosis in mammals, while in reptiles, this occurs by entosis $[29,35,36]$. The interstitium cell's fibroblasts and telocytes showed a communication via vesicles with the LC, suggesting cell to cell vesicles communication, hence these cells influenced the Leydig cell (LC) shape and testosterone production [37-39]. Hereafter, in past few decades the role of vesicles in cell-to-cell communication are of great interest in shaping their local environment by releasing factors that either effect adjacent cells or manipulate the biochemical properties of extracellular milieu [40]. The seasonal variation in the LC population is the indicative of interstitial precursor cells, that divide, then differentiate and replenish the LC numbers during testicular seasonal cycle [41]. Whereas the LC area related with steroidogenic activity based organelles such as SER that associated with androgen synthesis [42]. In contrast with present study results, In adults' rats, the significant increased numbers and area of Leydig cell treated with hCG (human chorionic gonadotrophin) and LH (Luteinizing hormone) was reported [43]. While in the seasonal Golden hamster the LCs area was 30\% reduced during inactive phase after photoinhibition [44] whereas in bat, the LCs became hypertrophied on the renewal of spermatogenesis [45]. During hi-

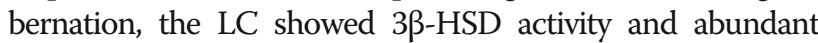
tubular endoplasmic reticulum (ER) by IHC and TEM, which suggested an increased area in Chrysemys picta and Chelydra serpentine $[30,46]$. These findings are also consistent with temperate-zone reptiles such as the lizard during different phases of the reproductive cycle [47]. The LC in turtles have the potential to become steroidogenic at any time of the year [48] and are known to contain tubular or SER at all times [46]. During reproductive activity, a similar consistency was found in present study by the weak expression of 33-HSD and the existence of tubule-vesicular ER by TEM in the LC, which indicated a persistent steroidogenic activity, whereas in the LC of mammals (hamster, rat, rabbit, dog, guinea pig), the amount of SER was related to the testosterone secretion [49]. Moreover, we observed numerous lipid droplets (LD) within the LC by ORO staining during hibernation. The strong immunopositive reaction of vimentin (intermediate filament) and their appearance around the LD by TEM reflected the integrative role of intermediate filaments within the LC for steroid biosynthesis by facilitating the LD, and these LDs are a source of cholesterol for steroidogenesis [50]. In mammals, a similar constant of vimentin positivity was reported [51] and an in-vitro analyses presumed the facilitation of LD for the mitochondria [52]. As a result, the direct contact of the mitochondria with the LD facilitates its expansion in mammals [53], which was morphologically (TEM) observed in the current study.

Our study, the first for a non-mammalian vertebrate, illustrates the lipophagy within the Leydig cell of the Chinese soft-shelled turtle, which has previously been well studied in mammals by using the traditional methods of electron microscopy [26, 27] and autophagic markers (ATG7, LC3 and p62). We observed that, phagophore appeared close to the LDs during hibernation, which is the initial step in autophagosome formation [54] through the expansion of the endoplasmic reticulum [16]. The autophagosome then fused the with lysosome to develop the autolysosome [16]. In an In-vitro study of the LC, this phenomenon was associated with steroid biosynthesis by providing cholesterol to the LD and was known as lipophagy [14]. This phenomenon included lysosomal lipolysis to release fatty acids to meet functional demands $[55,56]$. Hence, the current findings provided clear evidence of an autophagic to autolysosome (Fig. 8). Fascinatingly, we found lysosomes attached to LDs forming the autophagic tube and engulfing LDs (Fig. 7c and d, and 8). In yeast, 


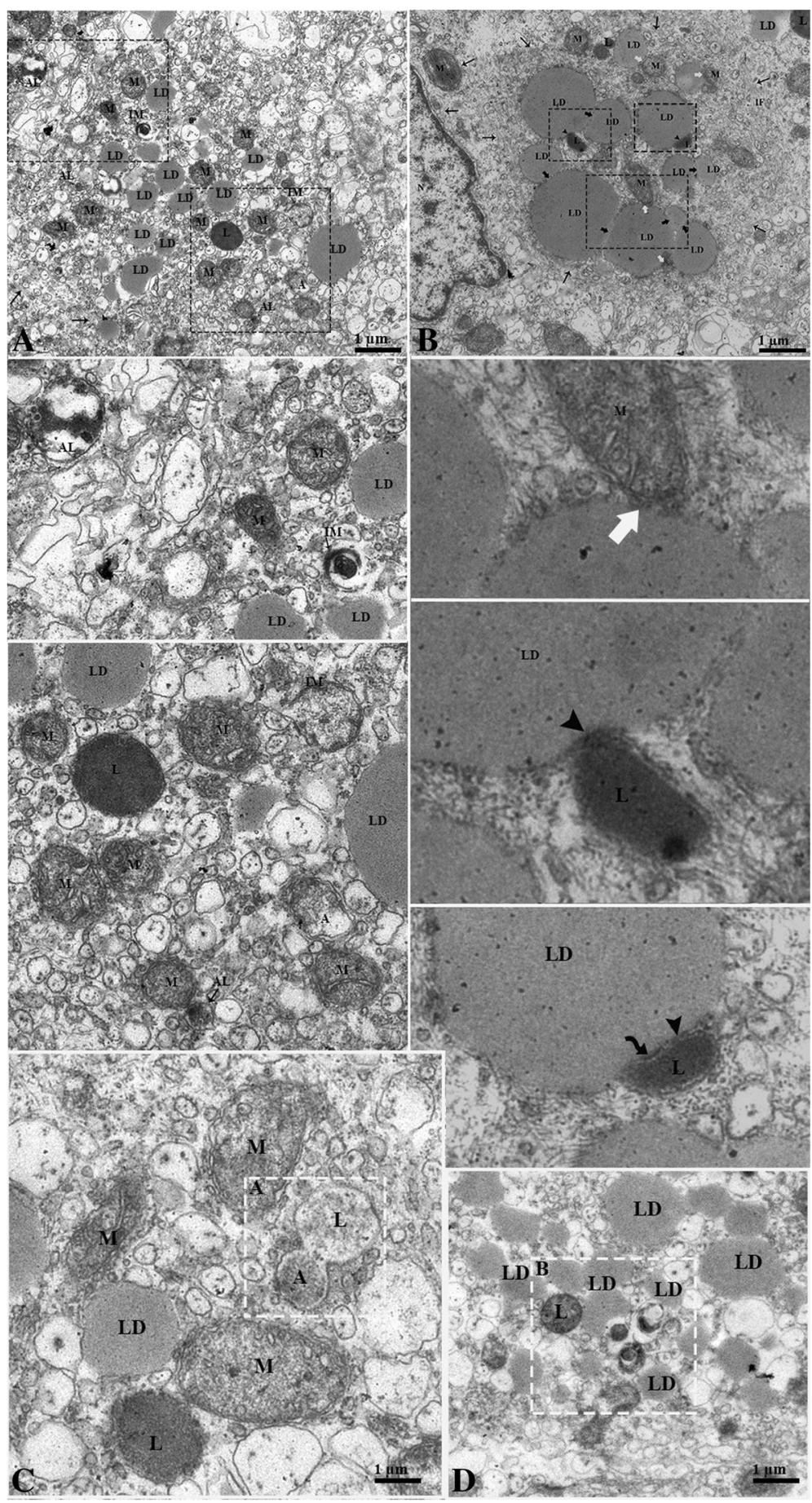

Fig. 8 Electron micrograph of lipid droplet mobilization during hibernation. (a) The Leydig cell contains numerous small lipid droplets that appear closely to the lysosome and mitochondria. (b) Large lipid droplets in contact with each other (black thick arrow) and with the lysosome (black head arrow) and mitochondria (white thick arrow). A curved arrow indicates the autophagic tube, (black arrow) intermediate filaments, (black rectangular area) autolysosome, autophagosome and isolated membrane. The white rectangular area indicates the (a) fusion of autophagosome and lysosome, and the (b) lysosomal engulfing of the LD. The illustration is of a higher magnification. LD: Lipid droplets; M: Mitochondria; L: Lysosome; A: Autophagosome; AL: Autolysosome; IM: Isolated Membrane. Scale bar = 1 um (a-d) 
Table 2 Ultrastructural Features of Leydig Cells during annual reproductive cycle of Chinese soft-shelled turtle

\begin{tabular}{lll}
\hline Features & Reproductive phase & Hibernation phase \\
\hline $\begin{array}{l}\text { Cluster Area } \\
/ \mathrm{mm}^{2}\end{array}$ & $0.72 \pm 0.1$ & $1.5 \pm 0.2$ \\
Nucleus & $\begin{array}{l}\text { Round with smooth } \\
\text { nuclear membrane } \\
\text { (diameter }=7.1 \pm 0.24 \mu \mathrm{m})\end{array}$ & $\begin{array}{l}\text { Oval to elliptical with } \\
\text { irregular nuclear membrane } \\
\text { (diameter }=6.9 \pm 0.35 \mu \mathrm{m})\end{array}$ \\
$\begin{array}{l}\text { Lipid } \\
\text { droplets }\end{array}$ & $\begin{array}{l}\text { Few (diameter }=0.84 \\
\pm 0.027 \mu \mathrm{m})\end{array}$ & $\begin{array}{l}\text { Numerous (diameter } \\
=1.1 \pm 0.08 \mu \mathrm{m})\end{array}$ \\
Mitochondria & Tubulo-vesicular cristae & \\
SER & Tubule-vesicular & Mainly tubular \\
Surface & $\begin{array}{l}\text { Less Interdigitation space } \\
\text { (finger like protrusions) }\end{array}$ & $\begin{array}{l}\text { More Interdigitation space } \\
\text { (finger like protrusions) }\end{array}$ \\
Arranged & Cluster & Cluster \\
\hline
\end{tabular}

micro-autophagy by autophagic tube engulfment has been described, but this has not yet been well characterized in other eukaryotes [17]. An in-vitro study using HeLa cells, concluded that LAMP1 and LAMP2 bind with cholesterol and are involved in cholesterol export [25]. Thus, for the TEM and immunofluorescence results, we suggest that macro-autophagy along with micro-autophagy were involved in the lipid metabolism. However, the lysosome is the endpoint of numerous vesicle trafficking pathways including for endocytosis, phagocytosis and autophagy [57]. To associate the function and activity of different autophagy types and abundant mitochondria, the lysosome and their attachment to LDs were observed during hibernation. This findings reflects that lipid metabolism releases the endogenous energy for steroidogenesis by different ways because the LDs are reserved as energy stock [58]. Furthermore, our findings demonstrate that the expression of specific autophagic markers are strongly expressed in the LC during hibernation compared to the reproductive phase. It has been suggested that the autophagy level was higher than other non-steroid-producing cells in mice and rats [27, 59] because of the increased cellular demand for autophagy imposed by the high turnover rate of steroid producing apparatus components [15]. Therefore, our autophagy marker and TEM findings are in line with the alteration of autophagy activity in turtle LC during the annual reproductive cycle.

\section{Conclusion}

In conclusion, the Leydig cells in the Chinese soft-shelled turtle, Pelodiscus sinensis possessed a dynamic steroidogenic activity (active 3 $\beta$-HSD), tubulo-vesicular ER, lipid droplets and tubular mitochondria during hibernation compared to the reproductive phase. Moreover, the current study provides novel morphological evidence on the involvement of lipophagy in mobilization of the LDs within the LC by two different modes (macro- and micro-phagy). This research indicates a new role for lipid metabolism in the LC of the turtle during the steroidogenesis process by autophagy.

\section{Funding \\ This research was supported by grants from the National Natural Science Foundation of China (Grant number: 31872433 and 31672505), Priority Academic Program Development of Jiangsu Higher Education Institutions, PR-China.}

\section{Availability of data and materials}

The dataset supporting the conclusions of this article are included within the article.

\section{Authors' contributions}

IT, WAV, XB, QC, MX, and YL designed and conducted the experiments. IT, $\mathrm{HC}, \mathrm{YH}, \mathrm{AH}$ and NSG analyzed the data. IT, QC, and PY wrote and revised the paper. All authors read and approved the final manuscript.

\section{Ethics approval and consent to participate}

All procedures described were reviewed and approved by the ethical committee for Science and Technology Agency of Jiangsu Province (SYXK (SU) 2010-0009). All animal care and use procedures were in accordance with the guidelines of the Science and Technology Agency of Jiangsu Province (SYXK (SU) 2010-0009).

\section{Consent for publication}

Not applicable.

\section{Competing interests}

The authors declare that they have no competing interests.

\section{Publisher's Note}

Springer Nature remains neutral with regard to jurisdictional claims in published maps and institutional affiliations.

\section{Author details}

${ }^{1} \mathrm{MOE}$ Joint international Research Laboratory of Animal Health and Food safety, College of Veterinary Medicine, Nanjing Agricultural University, Nanjing 210095, Jiangsu Province, China. 'Faculty of Veterinary and Animal Sciences, University of Poonch Rawalakot, Azad Kashmir, Pakistan.

Received: 19 November 2018 Accepted: 31 January 2019

Published online: 09 February 2019

\section{References}

1. Kumar S, Roy B, Rai U. Chapter 3 - hormonal regulation of testicular functions in reptiles. In: Norris DO, Lopez KH, editors. Hormones and reproduction of vertebrates. London: Academic Press; 2011. p. 63-88.

2. Teerds KJ, Huhtaniemi IT. Morphological and functional maturation of Leydig cells: from rodent models to primates. Hum Reprod Update. 2015; 21(3):310-28.

3. Galligan JH, Dunson WA. Biology and status of timber rattlesnake (Crotalus horridus) populations in Pennsylvania. Biol Conserv. 1979;15(1):13-58.

4. Gribbins KM, Elsey RM, Gist DH. Cytological evaluation of the germ cell development strategy within the testis of the American alligator, Alligator mississippiensis. Acta Zoologica. 2006;87(1):59-69.

5. Rheubert JL, McHugh HH, Collier MH, Sever DM, Gribbins KM. Temporal germ cell development strategy during spermatogenesis within the testis of the ground skink, Scincella lateralis (Sauria: Scincidae). Theriogenology. 2009; 72(1):54-61.

6. Xiangkun H, Li Z, Meiying L, Huijun B, Nainan H, Qiusheng C. Seasonal changes of sperm storage and correlative structures in male and female soft-shelled turtles, Trionyx sinensis. Anim Reprod Sci. 2008;108(3-4):435-45.

7. Colli GR, Pinho AA. Interstitial cell cycle of Ameiva ameiva (Sauria, Teiidae)in the Cerrado region of Central Brazil. J Morphol. 1997;233(2):99-104.

8. Grimalt PE, Castro LP, Mayorga LS, Bertini F. Epididymal acid hydrolases in the annual reproductive cycle of two lizards. Comp Biochem Physiol A Physiol. 1995;112(2):321-5. 
9. Vieira GHC, Wiederhecker H, Colli G, Báo S. Spermiogenesis and testicular cycle of the lizard $<i>$ Tropidurus torquatus $</ i>$ (Squamata, Tropiduridae) in the Cerrado of Central Brazil. Amphibia-Reptilia. 2001;22(2):217-33.

10. Ahmed N, Yang P, Huang Y, Chen H, Liu T, Wang L, et al. Entosis Acts as a Novel Way within Sertoli Cells to Eliminate Spermatozoa in Seminiferous Tubule. Front Physiol. 2017:8:361.

11. Ujjan N, Liu Y, Chen H, Yang P, Waqas Y, Liu T, et al. Novel cellular evidence of lipophagy within the Sertoli cells during spermatogenesis in the turtle. 2016.

12. Singh R, Kaushik S, Wang Y, Xiang Y, Novak I, Komatsu M, et al. Autophagy regulates lipid metabolism. Nature. 2009;458(7242):1131-5.

13. Ma Y, Zhou Y, Zhu Y-C, Wang S-Q, Ping P, Chen X-F. Lipophagy contributes to testosterone biosynthesis in male rat Leydig cells. Endocrinology. 2018; 159(2):1119-29.

14. Gao F, Li G, Liu C, Gao H, Wang H, Liu W, et al. Autophagy regulates testosterone synthesis by facilitating cholesterol uptake in Leydig cells. J Cell Biol. 2018;217(6):2103-19.

15. Yang W, Li L, Huang X, Kan G, Lin L, Cheng J, et al. Levels of Leydig cell autophagy regulate the fertility of male naked mole-rats. 2017.

16. Mizushima N, Komatsu M. Autophagy: renovation of cells and tissues. Cell. 2011;147(4):728-41.

17. Marzella L, Ahlberg J, Glaumann H. Autophagy, heterophagy, microautophagy and crinophagy as the means for intracellular degradation. Virchows Archiv B, Cell pathology including molecular pathology. 1981;36(2-3):219-34.

18. Thelen AM, Zoncu R. Emerging roles for the lysosome in lipid metabolism. Trends Cell Biol. 2017;27(11):833-50

19. Yoshii SR, Mizushima N. Monitoring and Measuring Autophagy. Int J Mol Sci. 2017;18:9.

20. Tanida I, Ueno T, Kominami E. LC3 and Autophagy. Methods in molecular biology (Clifton, NJ). 2008;445:77-88.

21. Liu WJ, Ye L, Huang WF, Guo LJ, Xu ZG, Wu HL, et al. p62 links the autophagy pathway and the ubiqutin-proteasome system upon ubiquitinated protein degradation. Cell Mol Biol Lett. 2016;21(1):29.

22. Yang Z, Klionsky DJ. An overview of the molecular mechanism of autophagy. Autophagy in infection and immunity: Springer; 2009. p. 1-32.

23. Xie Z, Klionsky DJ. Autophagosome formation: core machinery and adaptations. Nat Cell Biol. 2007:9(10):1102.

24. Feng $Y$, Yao Z, Klionsky DJ. How to control self-digestion: transcriptional, post-transcriptional, and post-translational regulation of autophagy. Trends Cell Biol. 2015;25(6):354-63.

25. Li J, Pfeffer SR. Lysosomal membrane glycoproteins bind cholesterol and contribute to lysosomal cholesterol export. elife. 2016;5.

26. TANG XM, CLERMONT Y, HERMO L. Origin and fate of autophagosomes in Leydig cells of Normal adult rats. J Androl. 1988;9(4):284-93.

27. Yi J, Tang XM. Functional implication of autophagy in steroid-secreting cells of the rat. Anat Rec. 1995;242(2):137-46.

28. Ahmed N, Yufei H, Yang P, Muhammad Yasir W, Zhang Q, Liu T, et al. Cytological study on Sertoli cells and their interactions with germ cells during annual reproductive cycle in turtle. Ecology and evolution. 2016; 6(12):4050-64.

29. Muñoz E, Fogal T, Dominguez S, Scardapane L, Guzmán J, Piezzi RS. Seasonal changes of the Leydig cells of viscacha (Lagostomus maximus maximus). A light and electron microscopy study. Tissue Cell. 1997;29(1):119-28.

30. Dubois W, Pudney J, Callard IP. The annual testicular cycle in the turtle, Chrysemys picta: a histochemical and electron microscopic study. Gen Comp Endocrinol. 1988;71(2):191-204.

31. Zhang L, Han XK, Qi YY, Liu Y, Chen QS. Seasonal effects on apoptosis and proliferation of germ cells in the testes of the Chinese soft-shelled turtle, Pelodiscus sinensis. Theriogenology. 2008;69(9):1148-58.

32. Lofts B, Tsui HW. Histological and histochemical changes in the gonads and epididymides of the male soft-shelled turtle, Trionyx sinensis. J Zool. 1977; 181(1):57-68.

33. Russell LD. The perils of sperm release-- 'let my children go'. Int J Androl. 1991;14(5):307-11.

34. O'Donnell L, Nicholls PK, O'Bryan MK, McLachlan RI, Stanton PG. Spermiation Spermatogenesis 2011;1(1):14-35

35. Dadhich RK, Barrionuevo FJ, Real FM, Lupianez DG, Ortega E, Burgos M, et al. Identification of live germ-cell desquamation as a major mechanism of seasonal testis regression in mammals: a study in the Iberian mole (Talpa occidentalis). Biol Reprod. 2013;88(4):101.

36. Liu T, Wang L, Chen H, Huang Y, Yang P, Ahmed N, et al. Molecular and Cellular Mechanisms of Apoptosis during Dissociated Spermatogenesis.
Front Physiol [Internet]. 2017 2017; 8:[188 p.]. Available from: http:// europepmc.org/abstract/MED/28424629, http://europepmc.org/articles/ PMC5372796?pdf=render, http://europepmc.org/articles/PMC5372796, https://doi.org/10.3389/fphys.2017.00188.

37. Vernon RB, Lane TF, Angello JC, Sage H. Adhesion, shape, proliferation, and gene expression of mouse Leydig cells are influenced by extracellular matrix in Vitro1. Biol Reprod. 1991;44(1):157-70.

38. Diaz ES, Pellizzari E, Meroni S, Cigorraga S, Lustig L, Denduchis B. Effect of extracellular matrix proteins on in vitro testosterone production by rat Leydig cells. Mol Reprod Dev. 2002;61(4):493-503.

39. Naraghi MA, Abolhasani F, Kashani I, Anarkooli IJ, Hemadi M, Azami A, et al. The effects of swimming exercise and supraphysiological doses of nandrolone decanoate on the testis in adult male rats: a transmission electron microscope study. Folia Morphol (Warsz). 2010;69(3):138-46.

40. Shifrin DA Jr, Demory Beckler M, Coffey RJ, Tyska MJ. Extracellular vesicles: communication, coercion, and conditioning. Mol Biol Cell. 2013;24(9):1253-9.

41. Hardy MP, Mendis-Handagama SMLC, Zirkin BR, Ewing LL. Photoperiodic variation of Leydig cell numbers in the testis of the golden hamster: a possible mechanism for their renewal during recrudescence. J Exp Zool. 1987;244(2):269-76

42. Ewing LL, Zirkin B. Leydig Cell Structure and Steroidogenic Function. In: Greep RO, editor. Proceedings of the 1982 Laurentian Hormone Conference. 39. Boston: Academic Press; 1983. p. 599-635.

43. Christensen AK, Peacock KC. Increase in Leydig cell number in testes of adult rats treated chronically with an excess of human chorionic gonadotropin. Biol Reprod. 1980;22(2):383-91.

44. Sinha Hikim AP, Bartke A, Russell LD. Morphometric studies on hamster testes in gonadally active and inactive states: light microscope findings. Biol Reprod. 1988;39(5):1225-37.

45. Gustafson AW. Changes in Leydig cell activity during the annual testicular cycle of the bat Myotis lucifugus lucifugus: histology and lipid histochemistry. Am J Anat. 1987;178(4):312-25.

46. Mahmoud IY, Cyrus RV, Bennett TM, Woller MJ, Montag DM. Ultrastructural changes in testes of the snapping turtle, Chelydra serpentina in relation to plasma testosterone, $\Delta 5$-3ß-hydroxysteroid dehydrogenase, and cholesterol. Gen Comp Endocrinol. 1985;57(3):454-64.

47. Vegni Talluri M, Bigliardi E. Interstitial testicular cells of the lizard Lacerta muralis brueggemanni during the seasonal cycle; 1983. p. 125-35.

48. Licht P, Breitenbach GL, Congdon JD. Seasonal cycles in testicular activity, gonadotropin, and thyroxine in the painted turtle, Chrysemys picta, under natural conditions. Gen Comp Endocrinol. 1985;59(1):130-9.

49. Zirkin BR, Ewing LL, Kromann N, Cochran RC. Testosterone secretion by rat, rabbit, Guinea pig, dog, and hamster testes perfused in vitro: correlation with ley dig cell ultrastructure*. Endocrinology. 1980;107(6):1867-74.

50. Azhar S, Reaven E. Regulation of Leydig cell cholesterol metabolism. In: Payne AH, Hardy MP, editors. The Leydig cell in health and disease. Totowa, NJ: Humana Press; 2007. p. 135-48.

51. Russell LD, Amlani SR, Vogl AW, Weber JE. Characterization of filaments within Leydig cells of the rat testis. Am J Anat. 1987;178(3):231-40.

52. Almahbobi G, Williams LJ, Han XG, Hall PF. Binding of lipid droplets and mitochondria to intermediate filaments in rat Leydig cells. J Reprod Fertil. 1993;98(1):209-17

53. Benador IY, Veliova M, Mahdaviani K, Petcherski A, Wikstrom JD, Assali EA, et al. Mitochondria Bound to Lipid Droplets Have Unique Bioenergetics, Composition, and Dynamics that Support Lipid Droplet Expansion. Cell Metabolism. 2018;27(4):869-85.e6.

54. Kim J, Huang WP, Klionsky DJ. Membrane recruitment of Aut7p in the autophagy and cytoplasm to vacuole targeting pathways requires Aut1p, Aut2p, and the autophagy conjugation complex. J Cell Biol. 2001;152(1):51-64

55. Dall'Armi C, Devereaux KA, Di Paolo G. The role of lipids in the control of autophagy. Curr Biol. 2013:23(1):R33-45.

56. Dong H, Czaja MJ. Regulation of lipid droplets by autophagy. Trends Endocrinol Metab. 2011;22(6):234-40.

57. He C, Klionsky DJ. Regulation mechanisms and signaling pathways of autophagy. Annu Rev Genet. 2009;43:67-93.

58. Hashemi HF, Goodman JM. The life cycle of lipid droplets. Curr Opin Cell Biol. 2015;33:119-24

59. Pfeifer U. Inhibition by insulin of the formation of autophagic vacuoles in rat liver. A morphometric approach to the kinetics of intracellular degradation by autophagy. J Cell Biol. 1978;78(1):152-67. 